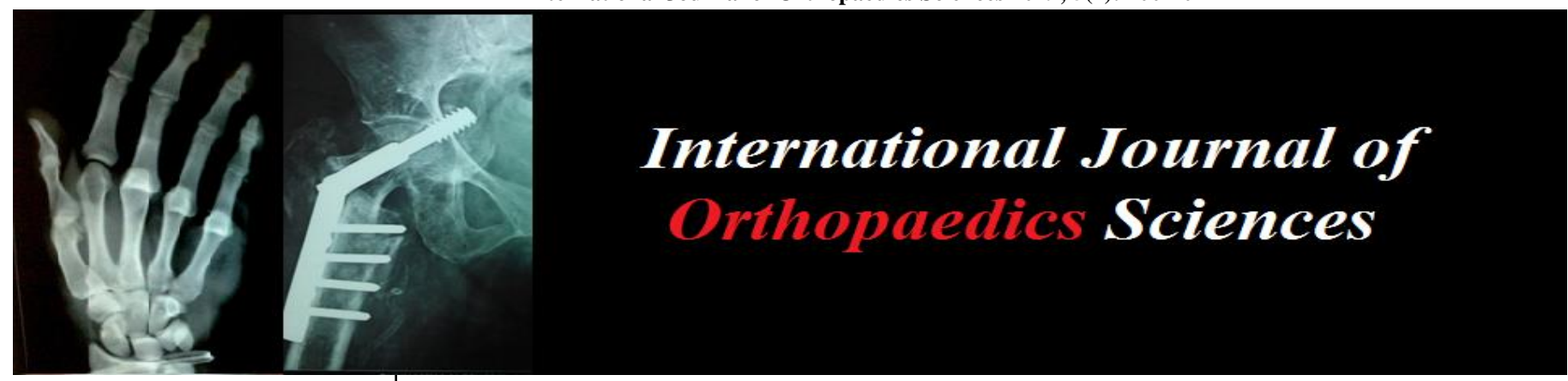

ISSN: 2395-1958

IJOS 2019; 5(1): 200-204

(C) 2019 IJOS

www.orthopaper.com

Received: 18-11-2018

Accepted: 21-12-2018

\section{Dr. Dhiyanesh K}

Asst. Prof, Dept. of

Orthopaedics, Mahatma Gandhi

Medical College, Sri Balaji

Vidyapeeth University,

Pondicherry, India

\section{Dr. Reguvaran}

Senior Resident, Asst. Prof,

Dept. of Orthopaedics, Mahatma

Gandhi medical College, Sri

Balaji Vidyapeeth University,

Pondicherry, India
Correspondence

Dr. Reguvaran

Senior Resident, Asst. Prof,

Dept. of Orthopaedics, Mahatma

Gandhi medical College, Sri

Balaji Vidyapeeth University,

Pondicherry, India

\title{
Functional and radiological outcome of lateral approach for hemiarthroplasty for hip
}

\section{Dr. Dhiyanesh K and Dr. Reguvaran}

DOI: https://doi.org/10.22271/ortho.2019.v5.i1d.38

\section{Abstract}

With increasing geriatric population, more number of femoral neck and trochanteric fractures are noted. Surgery being the gold standard for early mobilisation, less evidence exists on surgical approach. The aim of this study was to assess the functional and radiological outcome of lateral approach in patients of more than 55 years of age. 30 patients above 55 years of age with an acute fracture of the femoral neck, who underwent hemiarthroplasty through lateral approach, in the Department of Orthopaedics, MGMC\&RI, SBV university were followed up for 6 months and their functional and radiological outcomes assessed. The patients were of a mean age of 69.2. The mean Harris hip score was 77.5. There was no incidence of prosthetic dislocation, infection. Complications like Limb length discrepancy, myositis ossificans were noted. Abductor lurch were present which recovered with regular physiotherapy and ambulation. The use of Lateral approach to the hip in hemiarthroplasty showed excellent outcomes and no dislocation rates and hence the preferred approach for hemiarthroplasty.

Keywords: Harding's approach, hemiarthroplasty, neck of femur fracture

\section{Introduction}

Proximal femur fractures including intra and extra capsular fractures are expected to increase in incidence with increasing average life expectancy of individuals throughout the world. These fractures constitute the higher quotient in all osteoporotic fractures that occur in elderly age group ${ }^{[1]}$ It has been proved time and again that proximal fractures pose a great morbidity and mortality to the patient and economic burden to the society.

Conservative management of intracapsular fractures (neck of femur fracture, femoral head fractures) is associated with higher mortality in the first 30 days post trauma ${ }^{[2]}$. The surgical options available in 50 and below age group involve closed or open reduction and internal fixation. The options in elderly include hemi arthroplasty (monopolar or bipolar) or total hip replacement based on patient profiles, patients economic condition, personal preferences and training of the surgeon. Complications of anaesthesia and surgery far outweigh the complications of restricted mobility associated with non operative management, except in a very few who are unfit for surgery. The goal of this operation is to provide a stable, pain-free, mobile joint and making the patient mobile and non-dependent ${ }^{[3]}$.

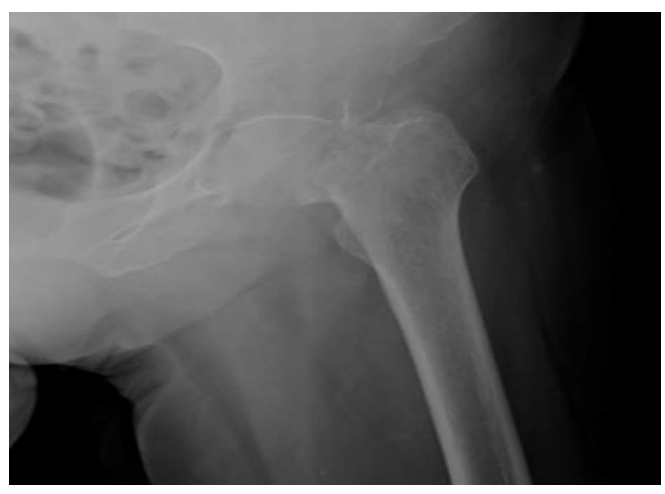

Fig 1: Intracapsular neck of femur fracture $\sim 200 \sim$

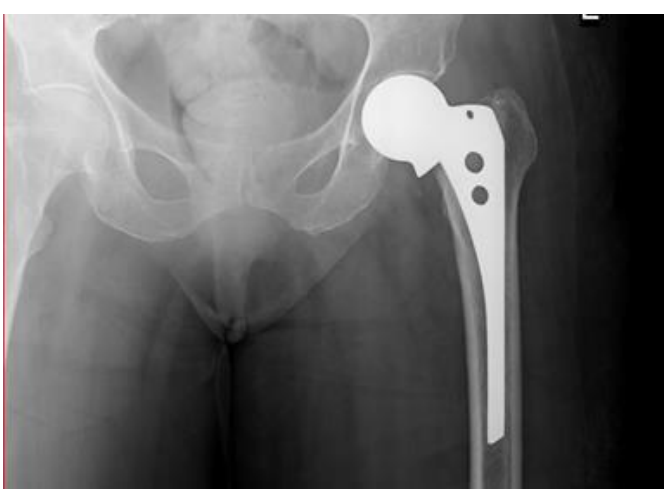

Fig 2: Austin moore prosthesis in situ 
Numerous new approaches to the hip have been described since the 1990s; most of the approaches are based on older approaches and are modified for a specific surgical procedure. Mainly two surgical approaches are performed while treating the fracture neck of femur with hemiarthroplasty. Posterior Approach is associated with an increased dislocation rate and revision rate due to dysfunction of the posterior soft tissue structures ${ }^{[4]}$. The lateral approach is associated with limping of the patient post surgery due to the damage to the abductor muscles ${ }^{[5]}$.

McFarland and Osborne described a lateral approach to the hip that preserves the integrity of the gluteus medius muscle. They noted that gluteus medius and vastus lateralis muscles can be regarded as being in direct functional continuity through the thick periosteum covering the greater trochanter and can be erased as a single unit from posterior to trochanter. Harding described a useful modification of the McFarland and Osborne direct lateral approach by reflecting the anterior half of this bundle. ${ }^{[6]}$ This approach can be easily made with the patient in supine position.

Frndak et al. modified the Harding's direct lateral approach by placing the abductor split more anterior, directly over femoral head and neck must not extend more than $2 \mathrm{~cm}$ above the lateral lip of the acetabulum to avoid damage to the gluteal neurovascular bundle ${ }^{[7]}$. This offers exposure of the femoral head and neck requires less retraction. McLauchlin described a direct lateral approach to the hip through the gluteus medius used for many years by Hay at the Stracathro Hospital. Omega incision was described by I.D. Learmonth, wherin a omega shaped incision is made in the Gluteus medius and vatus lateralis, retracting the gluteus medius, minimus along with few bone shingles from the aponeurotic junction of the greater trochanter ${ }^{[8]}$ So we have decided to study a short term follow up of functional outcome hemiarthroplasty done for neck of femur fractures through lateral approach using hardinge's approach.

\section{Materials}

The study was conducted in MGMC\&RI over a period of one and a half years following the ethical committee's approval.Thirty consecutive patients with fracture neck of femur admitted in the department of Orthopaedics through casualty/OPD who required Hemiarthroplasty were selected for the study.

\section{Methodology}

Patient with a suspected neck of femur was admitted in the casualty ward, he/she was clinically examined and analgesics were given to relieve pain. Traction was maintained during radiological examination to minimize the pain and the diagnosis was confirmed. X-ray of pelvis with both hip jointsanterior-posterior view, X-ray of involved side hip with femur full length-AP and lateral view were taken. This was followed by routine work up for surgery. Patients were detailed regarding the purpose of the study and surgery, all consents obtained. Garden's Classification of Fracture Neck of Femur. Skin traction was applied for the affected limb to reduce the pain. Pre-operative training was given on -Deep breathing exercises, Static quadriceps and calf muscle pumping exercises, strengthening exercises to upper limbs. We used Austin moore's prosthesis /bipolar prosthesis based on canal diameter and social background of the patient.

Lateral (Harding) approach under combined spinal +Epidural /spinal anaesthesia, patient was put in a lateral position with the affected hip facing upwards. After painting and draping the affected lower limb and hip a lazy $\mathrm{J}$ - incision centring over greater trochanter is made.
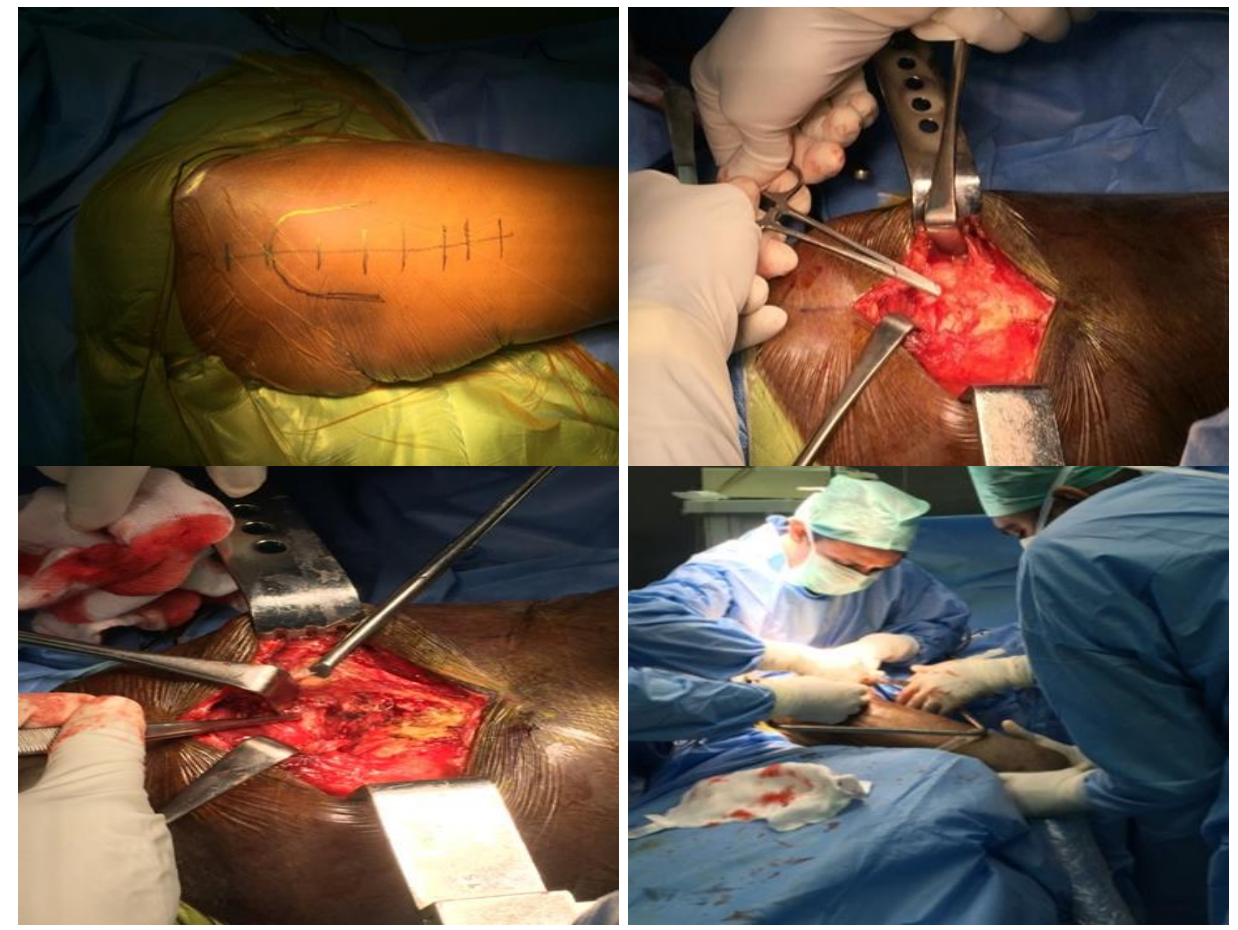

Fig 3-6: Shows marking of incision line with respect to greater trochanter, tendinous junction of gluteus medius and vastus lateralis and its incision ,dislocation of hip joint by flexion, adduction and internal rotation

Fascia lata is divided along skin incision. Tensor fascia lata is retracted anteriorly and gluteus maximus posteriorly. Tendinous junction of gluteus medius and vastuslateralis is exposed. An oblique incision is made over gluteus medius along the line of muscle fibres, across the greater trochanter leaving posterior two third still attached to the trochanter. This incision is carried proximally over the gluteus medius not more than $3 \mathrm{cms}$ and distally in line with vastuslateralis. 
The tendinous insertion of gluteus medius and vastuslateralis is elevated anteriorly. The capsule is visualised and ' $T$ 'incision was made.

The hip and knee was flexed and the limb was externally rotated and adducted. Femoral head is extracted with a corkscrew extractor, taking care not to damage the articular surface of acetabulum. Acetabulum is inspected and all loose debris and bone fragments were removed, along with the remnants of the ligamentum teres. The entry in the proximal femur is made with a box cut and then the femoral canal is prepared taking care to give adequate lateralisation of rasp. The femoral canal is broached by hand with a rasp in $5-10^{\circ}$ ante version and valgus position, During rasping decision is taken on use of cement depending on the size of the femoral canal. Head size of prosthesis was determined by measuring the head of femur, which was removed and measured with a measuring template. A trial reduction with the selected prosthesis was done. Range of movement, mobility and stability of the joint assessed. An appropriate size AMP/Bipolar Prosthesis is impacted with or without Bone cement in to the femoral canal. Care is taken while inserting the prosthesis to maintain adequate anteversion. Once the cement sets, prosthesis is then reduced by traction and internal rotation. The hip was tested for full range of movement and stability intra-operatively. Drill holes are made in the greater trochanter and 1 vicryl was used to anchor the abductors to the bone. The wound was closed meticulously in layers over suction drain maintaining haemostasis throughout the procedure and dressing was applied.
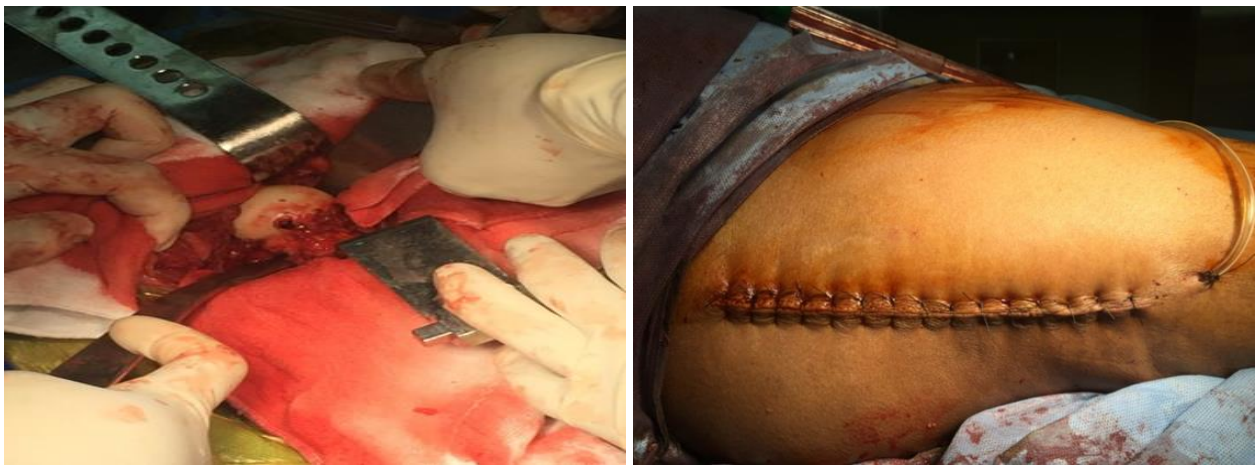

Fig 7 and 8: Shows exraction of femoral head and sutured surgical site respectively

3 doses of antibiotic were given post operatively. Analgesics were administered according to patient's analgesic requirements. The drain was removed on $2^{\text {nd }}$ Postoperative day. Static quadriceps exercises were advised to all the patients as soon as they recovered from the anaesthesia. All the patients were advised to sit up with back rest from the 1st postoperative day. Deep breathing exercises were advised. A post-operative check $\mathrm{x}$-ray was taken and the valgus seating with $10^{\circ}$ anteversion was confirmed. Any limb length discrepancy was noted. Knee flexion and isometric quadriceps exercises were started on $2^{\text {nd }}$ postoperative day and patients were mobilized with walkers with full weight bearing. They were discharged on post op Day 5.

The patient's were advised not to adduct or flex the hips beyond $90^{\circ}$ or involve in activities that place heavy loads or stresses on the hip for the next 3 weeks. They are advised to carry out exercises as advised pre op and advised to come for follow up at the end of second week of post-operative period for suture removal. For further follow up at 1 month, 3months and 6 months.At follow up, detailed clinical examination was done systematically. They were examined for gait, pain, tenderness, movements, deformities and length discrepancies. The distance the patient cover following surgery was questioned and compared to pre fracture state. The x-ray of the operated hip was taken at $1^{\text {st }}, 3^{\text {rd }}$ and $6^{\text {th }}$ month.

\section{Data Collection}

All data was entered into a Data Collection Performa Sheet and were entered into Excel (MS Excel 2011). Other biographical details were also collected including date of birth, weight and height.

\section{Statistical Methods}

The data were analyzed in the study using proportion and ChiSquare test as the results were of categorical values. Values of $p<0.05$ was considered statistically significant.

\section{Results and discussion}

A total number of 30 patients were selected on the basis of pre-defined inclusion and exclusion criteria after informed consent. All patients were recruited through the out-patient and the emergency services department of Orthopaedics, MGMC \&RI, SBV University, Pondicherry, INDIA.Majority of patients were between $61-70$ years old (46.7\%). and $30 \%$ of patients were between 71-80 years old and $13.3 \%$ of patients were between 50-60 years old. Females constituted $66.7 \%$ and Males 33.3\%.Majority of patients had domestic fall $(70 \%)$ and while $26.7 \%$ by RTA and $3.3 \%$ of patients by fall from height.

Table 1: Distribution by Mode of Injury

\begin{tabular}{|c|c|c|}
\hline Mode of Injury & Frequency & Percentage \\
\hline Domestic Fall & 21 & $70 \%$ \\
\hline Fall from Height & 1 & $3.3 \%$ \\
\hline RTA & 8 & $26.7 \%$ \\
\hline Total & 30 & $100 \%$ \\
\hline
\end{tabular}

Left side constituted (60\%) and $40 \%$ of the patients had injured their right side. Gardens type III fracture constituted $(43.4 \%)$ and $30 \%$ of the patients had gardens type IV and 23.3\% were under Garden's Type II and 3.3\% under Type I fractures

Table 2: Distribution by Gardens Type

\begin{tabular}{|c|c|c|}
\hline Gardens Type & Frequency & Percentage \\
\hline I & 1 & $3.3 \%$ \\
\hline II & 7 & $23.3 \%$ \\
\hline III & 13 & $43.4 \%$ \\
\hline IV & 9 & $30 \%$ \\
\hline Total & 30 & $100 \%$ \\
\hline
\end{tabular}


Uncemented hemiarthroplasty was done in $60 \%$. While $40 \%$ required cement due to wide canal.

Outcome was evaluated by clinical and radiological means. Clinical assessment was done by using the Harris Hip Score and surgical site infection. Radiological assessment was done based on the presence or absence of myositis ossificans, Prosthesis alignment, peri-prosthetic fracture and loosening. 30 cases of intra-capsular fracture neck of femur were managed by hemiarthroplasty, through hardinge lateral approach. We had excellent results in 12 cases (42.9\%), good in 12 cases $(42.9 \%)$, fair in 3 cases $(10.5 \%)$ and $1(3.5 \%)$ poor case, with an average score of 77 points according to the Harris hip rating system.

Table 3: Distribution by Harris Hip Score at 6 Months post op

\begin{tabular}{|c|c|c|}
\hline HHS on 6 $^{\text {th }}$ Month & Frequency & Percentage \\
\hline$<70$ & 1 & $3.5 \%$ \\
\hline $70-79$ & 4 & $10.5 \%$ \\
\hline $80-89$ & 12 & $42.9 \%$ \\
\hline $90-100$ & 12 & $42.9 \%$ \\
\hline Total & 28 & $100 \%$ \\
\hline
\end{tabular}

Among the 3 patients with fair results, one was a chronic alcoholic and did not fare better due to bad health and associated medical problems. The other was a 70 yrs old female, who was a housewife didn't fare well due to severe osteoarthritis knee which limited her mobility. Another patient developed myositis ossificans, which limited her hip abduction. Among the poor outcome group, patient had a proximal femur blowout due to domestic fall during her $1 \mathrm{st}$ month of post operative period.

We have got good (42.9\%) to excellent(42.9\%) results in $85.8 \%$ of the cases. In a series of 20 patients done by Dr.Sivakumar using lateral approach $20 \%$ of patients had excellent outcome, $60 \%$ of patients had good outcome, $20 \%$ had fair outcome. ${ }^{[12]} \mathrm{We}$ did total 30 cases of hemiarthroplasty in Hardinge's approach, at 3 months follow up we found excellent abductor muscle function in 20 patients, good in 5 patients and poor in 5 patients. After good physiotherapy, at 6 months' postoperative period we found excellent abductor muscle function in $26(85.7 \%)$ patients and poor in $2(14.3 \%)$ patients. Picado had $7.5 \%$ abductor lurch at 6 months post op. ${ }^{[9]}$

Table 4: Distribution by Abductor Lurch at 6 months

\begin{tabular}{|c|c|c|}
\hline Abductor Lurch & Frequency & Percentage \\
\hline Yes & 2 & $14.3 \%$ \\
\hline No & 26 & $85.7 \%$ \\
\hline Total & 28 & $100 \%$ \\
\hline
\end{tabular}

$23(76.6 \%)$ had no surgery related complications during the follow up period. $2(6.7 \%)$ of patients had lengthening and 2 $(6.7 \%)$ shortening and 1 had Myositis Ossificans which was detected at $3^{\text {rd }}$ month and was nonprogressive at the end of six months. 2 Patients lost their lives 3 months post surgery due to non surgery related health issues

Table 5: Distribution by Complications

\begin{tabular}{|c|c|c|}
\hline Complications & Frequency & Percentage \\
\hline Lengthening & 2 & $6.7 \%$ \\
\hline Shortening & 2 & $6.7 \%$ \\
\hline Myositis & 1 & $3.3 \%$ \\
\hline Expired & 2 & $6.7 \%$ \\
\hline Nil & 23 & $76.6 \%$ \\
\hline Total & 30 & $100 \%$ \\
\hline
\end{tabular}

In the reported series by Mulliken et al, in 770 patients operated using the above approach, they encountered $0.3 \%$ of dislocation rates, limp in $10 \%$, myositis in $3 \%$. $^{[10]}$ No Infection was encountered in our patients. In this study, there was no incidence of dislocation. We had limb length discrepancy in $4(13.4 \%)$ patients which was due to excessive or inadequate neck resection this was not due to the surgical approach.A recent meta analysis on the anterolateral and posterior approach over a period of five years shows no significant differences in dislocation rate ${ }^{[11]}$

\section{Conclusion}

After treating 30 patients with intracapsular fracture neck of femur, by Hemiarthroplasty through lateral approach, it has better advantage in terms of stability and functional results. There is reduced morbidity, with excellent to good results in 85.8\% and mean Harris hip score of 77 points. We did not encounter any dislocation in our series probably due to modified Hardinge Approach, better soft tissue balancing and as incision at non dependent part of body, better wound care and hence less chance of infection. Modified Hardinges approach is a excellent surgical approach if proper re-suturing of the abductor band and capsule closure is done. It requires a clear understanding of not to injure the superior gluteal nerve by limiting the proximal dissection of gluteus medius within 3 $\mathrm{cm}$ from tip of greater trochanter thus avoiding lurch in post operative period - the commonest complication of hardinge approach in early learners.

\section{Limitations}

We do not have a long term follow up to comment about the longevity of the prosthesis and the evidence on acetabular erosions. The study population of 30 patients is too small a number to give a statistically significant opinion and the study period was only for 6 months. Our early and short term results are encouraging and promising and long term results are awaited.

\section{References}

1. Shreyasee Amin, Osteoporosis in Men ( second Edition), The effects of gender on skeletal health, 2010, 351-360

2. One-year outcome for elderly patients with displaced intracapsular fractures of the femoral neck managed nonoperatively.Gregory JJ, Kostakopoulou K, Cool WP, Ford DJ.Injury. 2010; 41(12):1273-6.

3. Simon P, Gouin F, Veillard D, Laffargue P, Ehlinger M, Bel JC, et al. Rev Chir Orthop Reparatrice Appar Mot. 2008; 94(6):S108-32. Epub Sep 19

4. Bush JB, Wilson MR. Orthopedics. 2007; 30(2):138-44

5. Damage to the superior gluteal nerve following hardinge approach, M. Ramesh, J.M.O'Byrne, the bane and joint journal. 1996

6. A modified direct lateral approach in total hip arthroplasty,V.S.Pai, journal of orthopaedic surgery. 2002; 10(1):35-39

7. Frndak PA, Mallory TH, Lombardi AV. Translateral surgical approach to the hip: the abductor muscle "split". Clin Orthop Relat Res. 1993; 295:135

8. Learmonth D, Allen I. Patricia. The omega lateral approach to the hip. The Journal of bone and joint surgery. British. 1996; 78:559-61. 10.1302/0301620X.78B4.0780559.

9. Damage to the superior gluteal nerve after direct lateral approach to the hip. Picado $\mathrm{CH}$, Garcia FL, Marques W Jr. Clin Orthop Relat Res. 2007; 455:209-11. 
10. A modified direct lateral approach in total hip arthroplasty: a comprehensive review, Mulliken BD, Rorabeck CH, Bourne RB, Nayak N. J Arthroplasty. 1998; 13(7):737-47.

11. Does Surgical Approach Affect Outcomes in Total Hip Arthroplasty Through 90 Days of Follow-Up? A Systematic Review with Meta-Analysis, Larry E.MillerPhD, Joseph S.GonduskyMD, The Journal of arthroplasty. 2018; 33(4):1296-1302

12. z. A Prospective Study Comparing The Functional Outcome, Radiological Outcome and Gait Analysis between Lateral Surgical Approach and Posterior Surgical Approach in The Total Hip Replacement Dr.P.Sivakumar \& Prof. E.S.Arivazhagan, IOSR Journal of Dental and Medical Sciences. 2016; 15(9,V):20-44. 